\title{
Finite Element Analysis of Surcharge Preloading on Soft Ground Using Equivalent-load Method
}

\author{
Binbin XU1, a \\ ${ }^{1}$ Tianjin Port Engineering Institute Ltd. of CCCC, Tianjin, China; Key Lab. of Geotechnical \\ Engineering of Tianjin, Tianjin, China; Key Lab. of Geotechnical Engineering, Ministry of \\ Communication, Tianjin, China \\ axubinbin@tpei.com.cn
}

Keywords: FEM, Surcharge preloading, Equivalent-load method, Numerical analysis

Abstract. The surcharge preloading method is reproduced numerically in this paper. The plastic vertical drain is simulated using the drainage surface and the embankment is represented by equivalent load. The results show that the settlement and the pore pressure are correct, which can be used for the future engineering.

\section{Introduction}

Generally speaking, the ground improvement methods can be classified into four categories according to improvement mechanism, including roller compaction, drainage consolidation, replacement and cementation. Due to its economic and feasibility, the drainage consolidation is widely used in the improvement of soft ground. Compared to the vacuum preloading method, the surcharge preloading is free to the special equipment. During the improvement process, the concerning problem is the settlement during/after the improvement. Numerical calculation is the most common method to predict the settlement [1-4]. In this paper, the settlement of the ground is numerically calculated by regarding the embankment as equivalent load.

\section{Calculation scheme}

Mesh information and soil parameters. The mesh division is shown in Figure 1. As can be seen, the load is used to represent the embankment load. The normal constraints are applied on the four side surfaces and the fixed constraints are applied on the bottom surface.

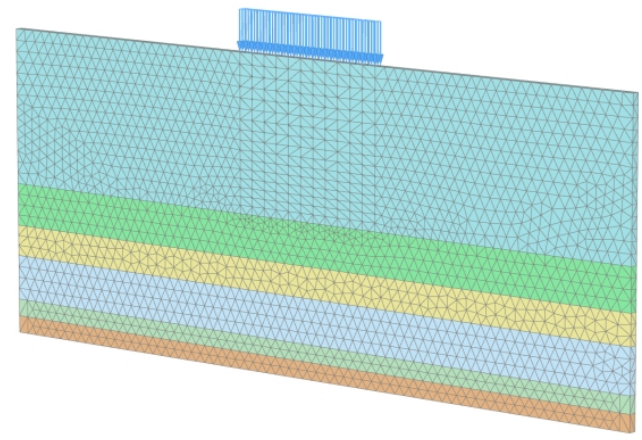

Figure 1 Mesh division

The ground is composed of 6 layers and the corresponding parameters are listed in Table 1. In the calculation, Mohr-column model is used. 
Table 1 Soil parameters

\begin{tabular}{|c|c|c|c|c|c|c|c|}
\hline NO. & Soil & $\begin{array}{l}\text { Bulk density } \\
\qquad\left(\mathrm{kN} / \mathrm{m}^{3}\right)\end{array}$ & $\begin{array}{c}\text { Young's } \\
\text { Modulus } \\
(\mathrm{kPa})\end{array}$ & $\begin{array}{l}\text { Poisson's } \\
\text { ratio }\end{array}$ & $\begin{array}{l}\text { Friction } \\
\text { angle }\left(^{\circ}\right)\end{array}$ & $\begin{array}{c}\text { Cohesive } \\
\text { strength } \\
(\mathrm{kPa})\end{array}$ & $\begin{array}{l}\text { Permeability } \\
(\mathrm{m} / \mathrm{d})\end{array}$ \\
\hline 1 & Mud & 16.4 & 1241 & 0.3 & 12.3 & 6.8 & $1.1 \mathrm{e}-4$ \\
\hline 2 & $\begin{array}{l}\text { Silty } \\
\text { clay }\end{array}$ & 19.8 & 3982 & 0.3 & 14.4 & 25.4 & $5.2 \mathrm{e}-4$ \\
\hline 3 & $\begin{array}{l}\text { Mucky } \\
\text { silty clay }\end{array}$ & 18.7 & 3098 & 0.3 & 18.0 & 14.5 & $1.2 \mathrm{e}-4$ \\
\hline 4 & Silt & 20.0 & 5690 & 0.3 & 30.2 & 12.0 & $5.7 e-3$ \\
\hline 5 & $\begin{array}{l}\text { Silty } \\
\text { clay }\end{array}$ & 19.6 & 3216 & 0.3 & 9.6 & 27.0 & $3.6 e-5$ \\
\hline 6 & Clay & 20.2 & 5478 & 0.3 & 28.5 & 24.3 & $3.6 e-5$ \\
\hline
\end{tabular}

Drainage passage. In Plaxis $\mathrm{AE}$, the drainage surface/line can be used to simulate the plastic vertical drain, where the excess pore pressure is set to be always zero so that the surrounding pore water can flow into the drainage surface. Therefore, in this simulation, the drainage surface is used to represent the plastic vertical drains and the interval space is $2 \mathrm{~m}$, as shown in Figure 2.

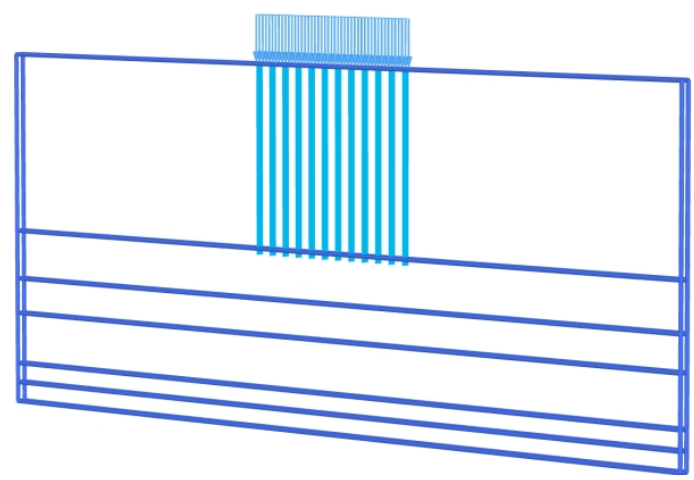

Figure 2 Layout of drainage passage

Construction stage. Considering the actual construction procedure, the numerical stages are listed as follows:

1) geostress balance to form the ground;

2) active the drainage surface to simulate the installation of plastic vertical drain;

3) apply $20 \mathrm{kPa}$ for each layer and after that place 20d;

4) repeat step 3 until 80kPa load;

5) consolidation to the end.

\section{Calculation results}

Settlement. The ground settlement after 110d surcharge preloading is shown in Figure 3. As can be seen, the maximum settlement occurs at the centre of the load and the influence depth is around $20 \mathrm{~m}$. Figure 4 demonstrates the settlement-time curve until 1100d. As can be seen, if the construction state is $100 \mathrm{~d}$, the consolidation degree is over $90 \%$. The existence of drainage passage helps to accelerate the consolidation of the ground. The layered settlement at different elevation is shown in Figure 5. During each load increase, the settlement increases greatly accordingly, after which the settlement gradually increases as the excess pore water dissipates. 


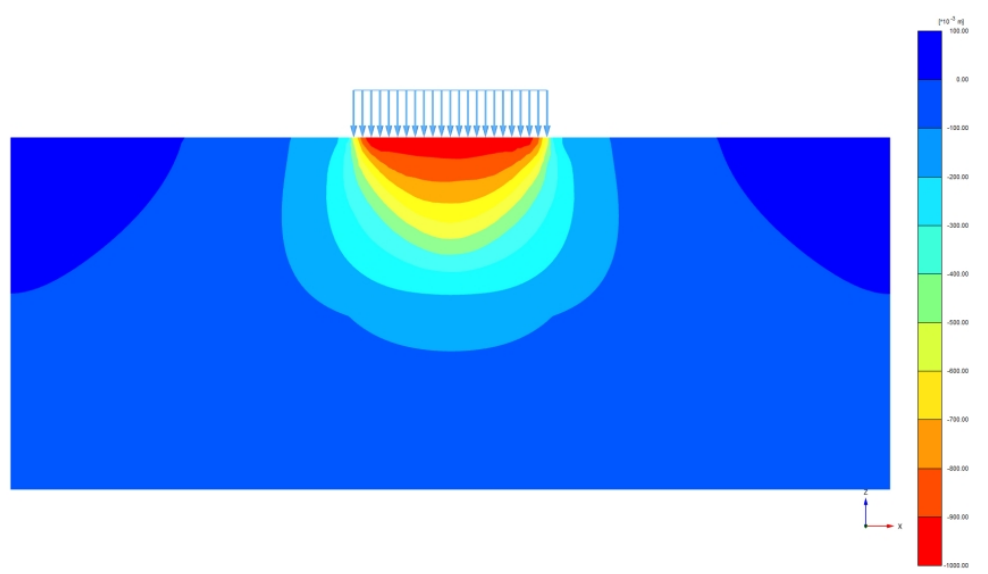

Figure 3 Distribution of settlement in the ground after 110d surcharge preloading

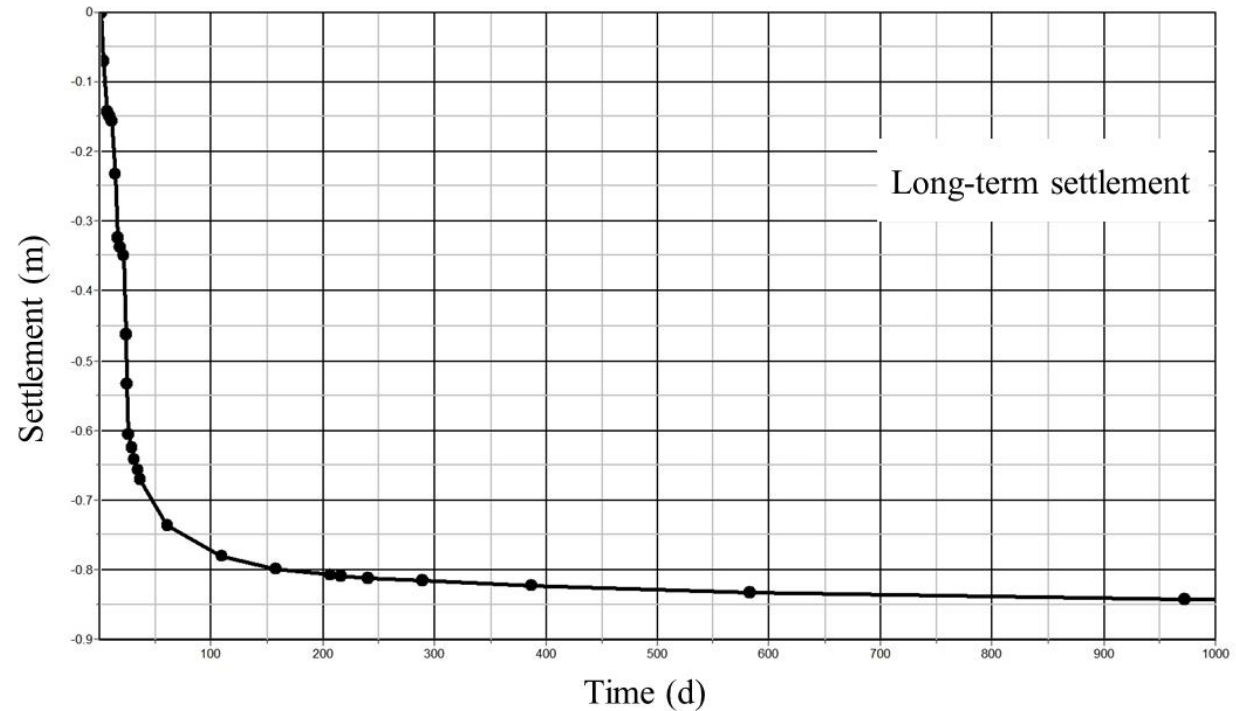

Figure 4 Settlement during/after construction

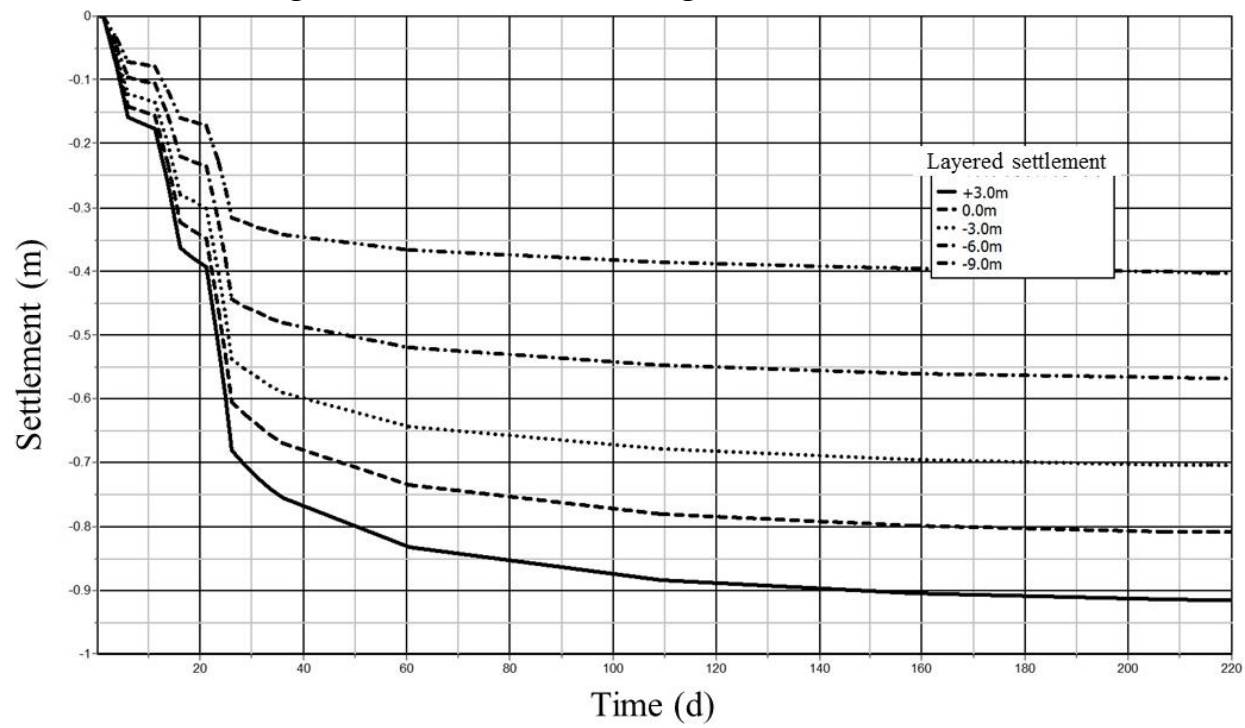

Figure 5 Layered settlements at the centre of embankment

Excess pore pressure. The distribution of excess pore pressure is shown in Figure 6 and the variation of excess pore pressure at different depths is shown in Figure 7. As can be seen, due to the existence of drainage surface, the excess pore pressure mainly concentrates between the surfaces and then soon dissipates. Also thanks to the drainage passage, the excess pore pressure is always smaller than the overburden effective stress so that the embankment is stable. 

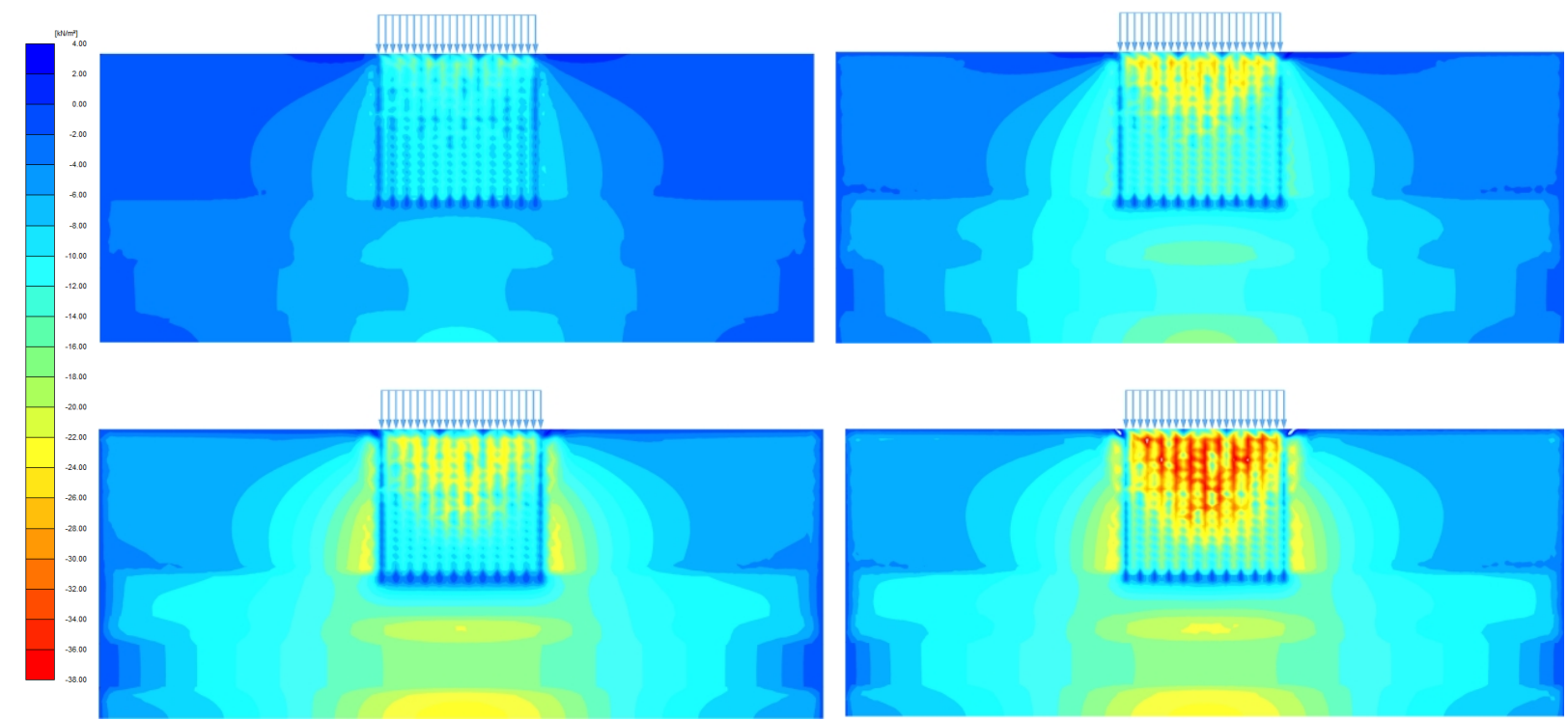

Figure 6 Distribution of excess pore pressure in the ground at different stages

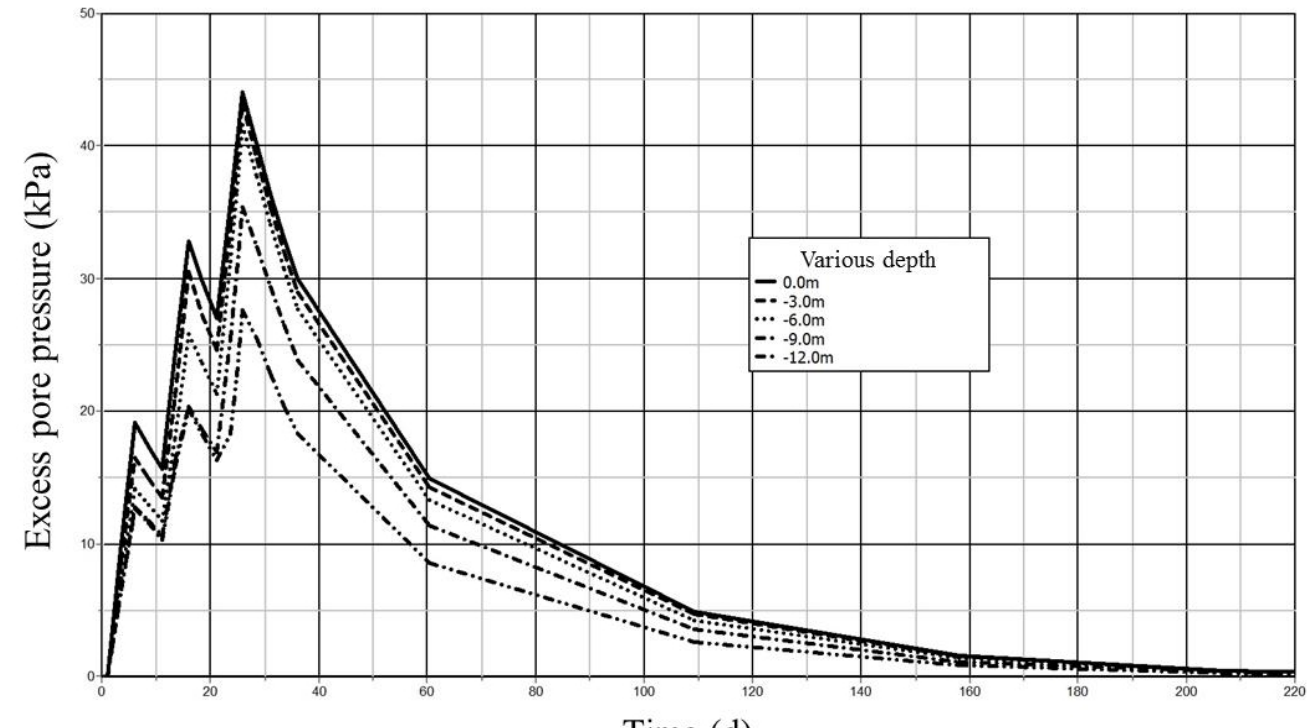

Time (d)

Figure 7 Dissipation of excess pore pressure at different depth in the ground

\section{Conclusions}

The surcharge preloading using equivalent load is numerically calculated. The plastic vertical drain is simulated using drainage surface. It is proved that the settlement and excess pore water pressure can be represented properly and the drainage surface can be used in the future drainage consolidation engineering.

\section{References}

[1] Chai J.C., Miura N., Sakajo S. and Bergado D., Japan Soc. Soil Mech. and Found. Eng., 1995, 35(4): 49-61.

[2] Indraratna B. and Redana I. W., J. Geotech. and Geoenviron. Engrg. ASCE. 1997(5): 474-478.

[3] Hird C. C., Pyrah I. C. and Russel D., Geotechnique, 1992(4):499-511.

[4] Mesri G. and Khan A.Q., J. Geotech. Geoenviron. Eng., 2012 138: 680-689. 